\title{
Detection and differentiation of Cryptosporidium by real-time polymerase chain reaction in stool samples from patients in Rio de Janeiro, Brazil
}

\author{
Roberta Flávia Ribeiro Rolando ${ }^{1}$, Sidnei da Silva ${ }^{2}$, Regina Helena Saramago Peralta ${ }^{3}{ }^{+}$, \\ Alexandre Januário da Silva ${ }^{4}$, Flavia de Souza Cunha ${ }^{3}$, Alexandre Ribeiro Bello ${ }^{1}$, José Mauro Peralta ${ }^{5}$ \\ ${ }^{1}$ Departamento de Microbiologia, Imunologia e Parasitologia, Universidade do Estado do Rio de Janeiro, Rio de Janeiro, RJ, Brasil \\ ${ }^{2}$ Instituto de Pesquisa Clínica Evandro Chagas-Fiocruz, Rio de Janeiro, RJ, Brasil ${ }^{3}$ Departamento de Patologia, Faculdade de Medicina, \\ Universidade Federal Fluminense, Niterói, RJ, Brasil ${ }^{4}$ Division of Parasitic Diseases and Malaria, Center for Global Health, \\ Centers for Disease Control and Prevention, Atlanta, GA, USA ${ }^{5}$ Instituto de Microbiologia Paulo de Góes, \\ Universidade Federal do Rio de Janeiro, Rio de Janeiro, RJ, Brasil
}

This study reports the first genetic characterisation of Cryptosporidium isolates in Brazil using real-time polymerase chain reaction (RT-PCR). A total of 1,197 faecal specimens from children and 10 specimens from human immunodeficiency virus-infected patients were collected between 1999-2010 and screened using microscopy. Forty-eight Cryptosporidium oocyst-positive isolates were identified and analysed using a generic TaqMan assay targeting the $18 \mathrm{~S}$ rRNA to detect Cryptosporidium species and two other TaqMan assays to identify Cryptosporidium hominis and Cryptosporidium parvum. The $18 S$ rRNA assay detected Cryptosporidium species in all 48 of the stool specimens. The C. parvum TaqMan assay correctly identified five/48 stool samples, while 37/48 stool specimens were correctly amplified in the $\mathrm{C}$. hominis TaqMan assay. The results obtained in this study support previous findings showing that $\mathrm{C}$. hominis infections are more prevalent than C. parvum infections in Brazil and they demonstrate that the TaqMan RT-PCR procedure is a simple, fast and valuable tool for the detection and differentiation of Cryptosporidium species.

Key words: Cryptosporidium - RT-PCR - molecular epidemiology

Species of the genus Cryptosporidium are recognised as important enteropathogens of immunocompetent and immunocompromised vertebrate hosts worldwide (Xiao \& Fayer 2008). To date, more than 20 species of Cryptosporidium have been recognised and at least eight species (Cryptosporidium hominis, Cryptosporidium parvum, Cryptosporidium meleagridis, Cryptosporidium felis, Cryptosporidium canis, Cryptosporidium suis, Cryptosporidium muris and Cryptosporidium andersoni) have been detected in humans (Chalmers \& Davies 2010).

Because the conventional methods for detecting Cryptosporidium oocysts cannot identify Cryptosporidium at the species level, molecular tools have been developed to detect and differentiate Cryptosporidium at the species/ genotype and subtype levels (Xiao \& Ryan 2004, Fayer 2010). Since the description of the first polymerase chain reaction (PCR)-based tool for differentiating between $C$. hominis and C. parvum (Morgan et al. 1995), other genotyping tools, including real-time PCR (RT-PCR), restriction fragment length polymorphism, microarray, melting curve analysis, single-strand conformation polymorphism analysis, random amplified polymorphic DNA PCR and DNA sequencing have been used in the characterisation of

Financial support: FAPERJ, SESDC, MS, CNPq

+Corresponding author: rperalta@vm.uff.br

Received 30 August 2011

Accepted 29 February 2012
Cryptosporidium epidemiology (Xiao \& Ryan 2008, Pangasa et al. 2009). Although tools based on the SSU rRNA region are the most widely used, other genetic targets (e.g., Cryptosporidium oocyst wall protein, $70-\mathrm{kDa}$ heat shock protein HSP70, thrombospondin-related adhesive protein of Cryptosporidium-1, dihydrofolate reductase and actin) can also detect and differentiate between Cryptosporidium species (Spano et al. 1998, Sulaiman et al. 2002, Xiao et al. 2002, Jiang \& Xiao 2003, Xiao 2010). Some recent studies have described a RT-PCR approach to detect and identify Cryptosporidium species (Higgins et al. 2001, Fontaine \& Guillot 2002, Limor et al. 2002, McDonald et al. 2002, Guy et al. 2003, Keegan et al. 2003, Jothikumar et al. 2008, Alonso et al. 2011).

In Brazil, there are several studies focusing on the occurrence of Cryptosporidium, but the molecular characterisation of the isolates is found in only few of these studies (Gonçalves et al. 2006, Bushen et al. 2007, Huber et al. 2007, Araújo et al. 2008).

In this study, we used a RT-PCR TaqMan procedure to detect Cryptosporidium species and to differentiate between C. hominis and C. parvum in stool specimens from children and human immunodeficiency virus (HIV)-infected patients from the state of Rio de Janeiro, Brazil.

\section{SUBJECTS, MATERIALS AND METHODS}

Faecal sample collection - A total of 1,197 faecal specimens from children and 10 specimens from HIV-infected patients (total $n=1,207$ ) were screened for intestinal parasite infections using a centrifuge-sedimentation technique. Briefly, $3 \mathrm{~mL}$ of diethyl ether was added to the washed faecal samples $(10 \mathrm{~mL})$ and the samples were 
vortexed for $30 \mathrm{~s}$ and then centrifuged at 2,500 rpm for 2 min (CELM, LS-3 plus). Both the fat layer and the supernatant were discarded and the pellet was suspended in $50 \mathrm{~mL}$ of grade water and centrifuged at 2,500 rpm for $2 \mathrm{~min}$. This washing procedure was repeated twice and the pellet was suspended in high purity grade water to a final volume of $5 \mathrm{~mL}$.

These stool samples were collected between 19992010 from a public day care and two different public hospitals in the city of Rio de Janeiro. For Cryptosporidium oocyst identification, stool samples were subjected to a modified Kinyoun acid-fast staining technique (Ma \& Soave 1983). After identification, all samples were stored at $4^{\circ} \mathrm{C}$ until molecular characterisation. This study was conducted with the approval of the Ethical Review Committee for Research, Faculty of Medicine, Rio de Janeiro State University.

DNA extraction - The extraction was based on a previously described protocol (Huber et al. 2007). Briefly, $200 \mu \mathrm{L}$ of faecal sample, $500 \mu \mathrm{L}$ of DNAzol 1 (Life Technologies, Carlsbad, CA), 0.5\% (final concentration) of polyvinylpyrrolidone (Sigma-Aldrich Corp, St. Louis, MO) and approximately $0.2 \mathrm{~g}$ of $425-600 \mathrm{~mm}$ diameter glass beads (Sigma) were added to a $1.5-\mu \mathrm{L}$ Eppendorf microtube. The microtubes were vortexed three times and incubated at $96^{\circ} \mathrm{C}$ for $60 \mathrm{~min}$. After centrifugation, the supernatant was transferred to another microtube, precipitated with $1 \mathrm{~mL}$ of pure ethanol and centrifuged again. The supernatant was discarded and the pellet was washed twice with $500 \mu \mathrm{L}$ of ethanol $(95 \%)$. After precipitation, the DNA was purified using a QIAamp ${ }^{\circledR}$ DNA Stool Kit (QIAGEN, Hilden, Germany) according to the manufacturer's protocol and was stored at $-20^{\circ} \mathrm{C}$ until further PCR reactions could be performed.

TaqMan PCR assays - primers and probes - The RTPCR procedure combined a duplex reaction for the detection of Cryptosporidium species and C. parvum and a simple reaction for the detection of $C$. hominis, as described previously (Jothikumar et al. 2008). To detect Cryptosporidium species, we used a TaqMan probe (JVAP18S), 5'Cy5-CGC-GCCTGCTGCCTTCCTTAGATG-BHQ-3', targeting the 18S rRNA. The sequence of the forward primer(JVAF)was5'-AT-GACGGGTAACGGGGAAT-3' and the sequence of the reverse primer (JVAR) was 5'CCAATTACAAAACCAAAAAGTCC-3'. The oligonucleotide sequences for the $C$. parvum TaqMan assay were 5'ACTTTTTGTTTGTTTTACGCCG-3' (JVAGF forward primer), 5'-AATGTGG-TAGTTGCGGTTGAA-3' (JVAGR reverse primer) and 5'-FAM-ATTTATCTCTTCGTAGCGGCG-BHQ-3' (JVAGP2 probe). The oligonucleotide sequences for the $C$. hominis TaqMan assay were 5'-ACTTTTTGT-TTGTTTTACGCCG-3'- (JVAGF forward primer), 5'-ATGTGGTAGTTGCGGTTGA-A-3' (JVAGR reverse primer) and 5'-FAM-ATTTATTAATTTATCTCTT-ACTTCGT-BHQ-3' (JVAGP1 probe).

TaqMan PCR assays - conditions - The PCR assays were performed with a 7500 System thermocycler (Life Technologies, Carlsbad, CA). Each $20 \mu \mathrm{L}$ duplex reaction (to identify Cryptosporidium species and C. parvum) contained $10 \mu \mathrm{L} 2 \mathrm{X}$ Platinum Quantitative PCR SuperMixUDG (Invitrogen), $100 \mathrm{nM}$ of each probe (JVAP 18S and JVAGP2), $250 \mathrm{nM}$ of each primer (JVAF, JVAR, JVAGF and JVAGR) and $5 \mu \mathrm{L}$ of DNA. For the $C$. hominis assay, each $20 \mu \mathrm{L}$ reaction contained $10 \mu \mathrm{L} 2 \mathrm{X}$ Platinum Quantitative PCR SuperMix-UDG (Invitrogen), $250 \mathrm{nM}$ of each primer (JVAF, JVAR, JVAGF and JVAGR), $5 \mathrm{mM}$ $\mathrm{MgCl}_{2}$, twice the probe concentration used for the duplex assay $(200 \mathrm{nM})$ and $5 \mu \mathrm{L}$ of DNA. The Cryptosporidium PCR cycling conditions consisted of denaturation at $95^{\circ} \mathrm{C}$ for 2 min followed by 45 cycles of denaturation at $94^{\circ} \mathrm{C}$ for $10 \mathrm{~s}$, annealing at $55^{\circ} \mathrm{C}$ for $30 \mathrm{~s}$ and extension at $72^{\circ} \mathrm{C}$ for $20 \mathrm{~s}$. All assays included positive controls (C. hominis and C. parvum) and negative controls (DNA extracted from faecal samples negative for any parasites).

\section{RESULTS}

A total of 48 faecal samples (38 from children and 10 from HIV-infected patients) were positive for Cryptosporidium oocysts using the modified Kinyoun acidfast staining technique. These samples were subjected to RT-PCR assays. The results of the dual TaqMan PCR procedure for the stool specimens from the children and the HIV-infected patients are shown in Table. For the 48 positive faecal sample isolates, the 18S rRNA TaqMan assay detected Cryptosporidium species in all 48 specimens. Five samples ( 1 from the HIV-infected group and 4 from children) were amplified in the C. parvum

TABLE

Differentiation of Cryptosporidium species by using polymerase chain reaction TaqMan procedure applied to faecal samples from children and human immunodeficiency virus (HIV) patients at the city of Rio de Janeiro, Brazil

\begin{tabular}{lcccc}
\hline & \multicolumn{4}{c}{ Cryptosporidium species } \\
\cline { 2 - 5 } Group ofstool samples & Cryptosporidium sp. & Cryptosporidium hominis & Cryptosporidium parvum & \multirow{2}{*}{ Total } \\
\hline Children & $6^{a}$ & 28 & 4 & 38 \\
HIV-infected patients & - & 9 & 1 & 10 \\
\hline Total & $6^{a}$ & 37 & 5 & 48 \\
\hline
\end{tabular}

$a$ : positive only in the $18 \mathrm{~S}$ rRNA assay. 
assay. The other nine samples from HIV-infected patients and 28 samples from children were amplified in the $C$. hominis assay. Six specimens previously determined to be Cryptosporidium-positive were reported as Cryptosporidium-negative using PCR and $18 \mathrm{~S}$ sequencing (data not shown), but were determined to be positive using the $18 \mathrm{~S}$ rRNA TaqMan assay. Neither $C$. hominis nor $C$. parvum were identified as being present in these six specimens. The $C$. hominis TaqMan probe did not cross-react with any of the $C$. parvum controls and the C. parvum TaqMan probe did not cross-react with the $C$. hominis controls or the negative controls.

\section{DISCUSSION}

This study reports a dual TaqMan assay procedure for the epidemiological investigation of cryptosporidiosis and is the first to report on the application of a RTPCR method for detecting and differentiating between Cryptosporidium species in Brazil.

A total of 48 specimens were analysed. The $18 \mathrm{~S}$ rRNA TaqMan PCR assay was able to detect the presence of Cryptosporidium DNA in all 48 specimens. C. hominis and $C$. parvum were detected in 37 and five DNA specimens, respectively, indicating the absence of mixed infections (samples containing both species). The same 18S rRNA TaqMan PCR assay protocol also detected the presence of Cryptosporidium DNA in 67 of 103 specimens $(65 \%)$ in an epidemiological investigation of cryptosporidiosis in USA and Botswana (Jothikumar et al. 2008). Our results showed that the TaqMan PCR assay can detect Cryptosporidium DNA efficiently and allowed for the differentiation of $C$. hominis and C. parvum at the species level. However, six samples were amplified only by the 18S rRNA TaqMan assay, indicating that other Cryptosporidium species involved in human cryptosporidiosis could be present in these samples. In this case, other molecular tools can be used to detect different Cryptosporidium species that are less prevalent in human infections.

Recent studies using RT-PCR procedures have reported molecular characterisations of Cryptosporidium spp and have differentiated between $C$. hominis and $C$. parvum (Higgins et al. 2001, McDonald et al. 2002, Guy et al. 2003). These authors described a RT-PCR assay for the quantification of Cryptosporidium, but the primerprobe set they developed was not able to differentiate between Cryptosporidium species. Alonso et al. (2011) evaluated the performance of a locked nucleic acid (LNA) TaqMan probe in a RT-PCR assay to quantify Cryptosporidium and Giardia. This RT-PCR assay was able to detect C. hominis, C. parvum, C. meleagridis and Cryptosporidium wrairi, but was not able to discriminate among these species. Tanriverdi et al. (2002) described a fluorescence resonance energy transfer (FRET) probe assay for differentiating between $C$. hominis and C. parvum, but the sensitivity of the test was not reported. Limor et al. (2002) also reported a FRET probe PCR assay, but the probe-primer set they used did not efficiently differentiate between C. hominis and C. parvum.

The results of our study show that $C$. hominis infections are more common than C. parvum infections in the studied region. With some exceptions, C. hominis is the predominant species in humans across the world (Gatei et al. 2006, 2007, 2008, Cama et al. 2007, Hung et al. 2007). In Brazil, the predominance of $C$. hominis over C. parvum is also known. Araújo et al. (2008) identified eight C. hominis, four C. parvum and two C. meleagridis species in isolates obtained from stool samples from HIV-infected patients and immunocompetent children in the state of São Paulo (SP). Another study conducted in SP revealed the presence of $C$. hominis in all 29 stool samples analysed during an outbreak at a day care centre (Gonçalves et al. 2006). A third study performed in the municipality of São Paulo (Lucca et al. 2009) reported that among 27 isolates from HIV infected patients, 17 were $C$. hominis $(63 \%)$, four were $C$. parvum $(14,8 \%)$, five were $C$. felis $(18,5 \%)$ and one was $C$. canis $(3,7 \%)$. Additionally, in Northeast Brazil, Bushen et al. (2007) reported the predominance of $C$. hominis (57.1\%) over $C$. parvum (42.9\%) among 42 isolates from children.

Recent molecular epidemiological studies have improved the knowledge of human cryptosporidiosis. $C$. parvum and $C$. hominis are associated with most foodborne, waterborne and direct contact-associated (i.e., person-to-person and animal-to-person) outbreaks of cryptosporidiosis (Xiao \& Ryan 2008). Some studies in Brazil have demonstrated that the anthroponotic cycle of cryptosporidiosis appears to be of more relevance than the zoonotic cycle (Gonçalves et al. 2006, Sevá et al. 2010). Our findings also suggest the predominance of the anthroponotic cycle in the studied area, but new genotyping studies are necessary to understand the transmission dynamics of human cryptosporidiosis in our region.

RT quantitative PCR methodology has been used to develop high-throughput screening assays for a variety of applications. The results of the dual TaqMan assays for the stool specimens from Brazil reported in this study demonstrated that the RT-PCR procedure targeting the 18S rRNA (a multicopy gene) was able to detect the presence of Cryptosporidium species and is a valuable tool for rapid differentiation between $C$. hominis and C. parvum in stool specimens collected for epidemiological investigations.

\section{REFERENCES}

Alonso JL, Amorós I, Canigral I 2011. Development and evaluation of a real-time PCR assay for quantification of Giardia and Cryptosporidium in sewage samples. Appl Microbiol Biotechnol 89: 1203-1211.

Araújo AJ, Kanamura HY, De Almeida ME, Gomes AHS, Pinto THL, Da Silva AJ 2008. Genotypic identification of Cryptosporidium spp isolated from HIV-infected patients and immunocompetent children of São Paulo, Brazil. Rev Inst Med Trop S Paulo 50: 139-143.

Bushen OY, Kohli A, Pinkerton RC, Dupnik K, Newman RD, Sears CL, Fayer R, Lima AA, Guerrant RL 2007. Heavy cryptosporidial infections in children in Northeast Brazil: comparison of Cryptosporidium hominis and Cryptosporidium parvum. Trans Roy Soc of Trop Med Hyg 101: 378-384.

Cama VA, Ross JM, Crawford S, Kawai V, Chavez-Valdez R, Vargas D, Vivar A, Ticona E, Navincopa M, Williamson J, Ortega Y, Gilman RH, Bern C, Xiao L 2007. Differences in clinical manifestations among Cryptosporidium species and subtypes in HIVinfected persons. J Infect Dis 196: 684-691. 
Chalmers RM, Davies AP 2010. Minireview: clinical criptosporidiosis. Exp Parasitol 124: 138-146.

Fayer R 2010. Taxonomy and species delimitation in Cryptosporidium. Exp Parasitol 124: 90-97.

Fontaine M, Guillot E 2002. Development of a TaqMan quantitative PCR assay specific for Cryptosporidium parvum. FEMS Microbiol Lett 214: 13-17.

Gatei W, Barrett D, Lindo JF, Eldemire-Shearer D, Cama V, Xiao L 2008. Unique Cryptosporidium population in HIV-infected persons, Jamaica. Emerg Infect Dis 14: 841-843.

Gatei W, Das P, Dutta P, Sen A, Cama V, Lal AA, Xiao L 2007. Multilocus sequence typing and genetic structure of Cryptosporidium hominis from children in Kolkata, India. Infect Genet Evol 7: 197-205.

Gatei W, Wamae CN, Mbae C, Waruru A, Mulinge E, Waithera T, Gatika SM, Kamwati SK, Revathi G, Hart CA 2006. Cryptosporidiosis: prevalence, genotype analysis and symptoms associated with infections in children in Kenya. Am J Trop Med Hyg 75: 78-82.

Gonçalves EM, da Silva AJ, Eduardo MB, Uemura IH, Moura INS, Castilho VLP, Corbett CEP 2006. Multilocus genotyping of Cryptosporidium hominis associated with diarrhea outbreak in a day care unit in São Paulo. Clinics 61: 119-126.

Guy RA, Payment P, Krull UJ, Horgen PA 2003. Real-time PCR for quantification of Giardia and Cryptosporidium in environmental water samples and sewage. Appl Environ Microbiol 69: 5178-5185.

Higgins JA, Jenkins MC, Shelton DR, Fayer R, Karns JS 2001. Rapid extraction of DNA from Escherichia coli and Cryptosporidium parvum for use in PCR. Appl Environ Microbiol 67: 5321-5324.

Huber F, da Silva S, Bonfim TCB, Teixeira KRS, Bello AR 2007. Genotypic characterization and phylogenetic analysis of Cryptosporidium sp. from domestic animals in Brazil. Vet Parasitol 30: 65-74.

Hung CC, Tsaihong JC, Lee YT, Deng HY, Hsiao WH, Chang SY, Chang SC, Su KE 2007. Prevalence of intestinal infection due to Cryptosporidium species among Taiwanese patients with human immunodeficiency virus infection. J Formos Med Assoc 106: 31-35.

Jiang J, Xiao L 2003. An evaluation of molecular diagnostic tools for the detection and differentiation of human-pathogenic Cryptosporidium spp. J Eukaryot Microbiol 50: 542-547.

Jothikumar N, da Silva AJ, Moura I, Qvarnstrom Y, Hill VR 2008. Detection and differentiation of Cryptosporidium hominis and Cryptosporidium parvum by dual TaqMan assays. J Med Microbiol 57: 1099-1105.

Keegan AR, Fanok S, Monis PT, Saint CP 2003. Cell culture-TaqMan PCR assay for evaluation of Cryptosporidium parvum disinfection. Appl Environ Microbiol 69: 2505-2511.

Limor JR, Lal AA, Xiao L 2002. Detection and differentiation of Cryptosporidium parasites that are pathogenic for humans by real-time PCR. J Clin Microbiol 40: 2335-2338.
Lucca P, De Gaspari EN, Bozzoli LM, Funada MR, Silva SOS, Wilma I, Soares RM 2009. Molecular characterization of Cryptosporidium spp from HIV infected patients from an urban area of Brazil. Rev Inst Med Trop S Paulo 51: 341-343.

Ma P, Soave R 1983. Three-step stool examination for cryptosporidiosis in 10 homosexual men with protracted watery diarrhea. J Infect Dis 147: 824-828.

McDonald LM, Sargent K, Armson A, Thompson RC, Reynoldson JA 2002. The development of a real-time quantitative-PCR method for characterization of a Cryptosporidium parvum in vitro culturing system and assessment of drug efficacy. Mol Biochem Parasitol 121: 279-282.

Morgan UM, Constantine CC, O’Donoghue P, Meloni BP, O’Brien PA, Thompson RC 1995. Molecular characterization of Cryptosporidi$u m$ isolates from humans and others animals using random amplified polymorphic DNA analysis. Am J Trop Med Hyg 52: 559-564.

Pangasa A, Jex AR, Campbell BE, Bott NJ, Whipp M, Hogg G, Stevens MA, Gasser RB 2009. High resolution melting-curve (HRM) analysis for the diagnosis of cryptosporidiosis in humans. Mol Cell Probes 23: 10-15.

Sevá AP, Funada MR, Souza SO, Nava A, Richtzenhain LJ, Soares RM 2010. Occurrence and molecular characterization of Cryptosporidium spp isolated from domestic animals in a rural area surrounding Atlantic dry forest fragments in Teodoro Sampaio municipality, state of São Paulo, Brazil. Rev Bras Parasitol Vet 19: 249-253.

Spano F, Putignani L, Crisanti A, Sallicandro P, Morgan UM, Le Blancq SM, Tchack L, Tzipori S, Widmer G 1998. Multilocus genotypic analysis of Cryptosporidium parvum isolates from different hosts and geographical origins. J Clin Microbiol 36: 3255-3259.

Sulaiman IM, Lal AA, Xiao L 2002. Molecular phylogeny and evolutionary relationships of Cryptosporidium parasites at the actin locus. J Parasitol 88: 388-394.

Tanriverdi S, Tanyeli A, Baslamisli F, Koksal F, Kilinc Y, Feng X, Batzer G, Tzipori S, Widmer G 2002. Detection and genotyping of oocysts of Cryptosporidium parvum by real-time PCR and melting curve analysis. J Clin Microbiol 40: 3237-3244.

Xiao L 2010. Molecular epidemiology of cryptosporidiosis: an update. Exp Parasitol 124: 80-89.

Xiao L, Fayer R 2008. Molecular characterization of species and genotypes of Cryptosporidium and Giardia and assessment of zoonotic transmission. Int J Parasit 38: 1239-1255.

Xiao L, Ryan UM 2004. Cryptosporidiosis: an update in molecular epidemiology. Curr Opin Infect Dis 17: 483-490.

Xiao L, Ryan UM 2008. Molecular epidemiology. In R Fayer, L Xiao, Cryptosporidium and cryptosporidiosis, CRC Press/IWA Publishing, Boca Raton, p. 119-171.

Xiao L, Sulaiman IM, Ryan UM, Zhou L, Atwill ER, Tischler ML, Zhang X, Fayer R, Lal AA 2002. Host adaptation and host-parasite co-evolution in Cryptosporidium: implications for taxonomy and public health. Int J Parasitol 32: 1773-1785. 